\title{
Thermo-Mechanical Analysis of the Sealing Performance of a Diesel-Engine Cylinder Gasket
}

\section{Xulan Wang ${ }^{1, *}$, Zezhong Chen ${ }^{1}$, Changzhen Liu $^{1}$, Wei Ren ${ }^{2}$, Bo Wu ${ }^{1}$, Shude Ji ${ }^{1}$, Xiaofei Chen ${ }^{1}$, Shijie Wen ${ }^{1}$ and Yonggang Hao ${ }^{1}$}

${ }^{1}$ System Engineering Institute, China North Engine Research Institute, Tianjin, 300400, China

${ }^{2}$ Engine Department, BAIC Motor Co., Ltd., Beijing, 101106, China

*Corresponding Author: Xulan Wang. Email: jvlihaoyuan5@outlook.com

Received: 22 October 2020 Accepted: 15 March 2021

\begin{abstract}
Taking the combustor composite structure of a high-strength diesel engine as the main research object, dedicated tests have been conducted to verify the accuracy of three distinct cylinder gasket pressure simulation models. Using the measured cylinder gasket compression rebound curve, a gasket unit has been designed and manufactured. For this unit, the influence of the bolt pretension, cylinder body and cylinder head material on gasket sealing pressure has been investigated systematically in conditions of thermo-mechanical coupling. The results show that the bolt pretension force is one of the most important factors affecting the cylinder gasket sealing pressure. The change of the body material has little effect on this pressure. The cylinder gasket seal pressure decreases progressively with the reduction of the elastic module of the cylinder head material.
\end{abstract}

\section{KEYWORDS}

Cylinder gasket; bolt pretension force; sealing; cylinder head material

\section{Introduction}

Diesel engine combustion occurs in a combustion chamber which is enclosed by the cylinder head bottom, the cylinder liner, the piston top and the cylinder gasket. The cylinder gasket, located between the cylinder block and the cylinder head, acts as a critical sealing part to avoid the burned gas from leaking. It not only bears the pretension exerted by the cylinder head bolt, but also suffers high temperature, high pressure and additional force between the joint surfaces [1-6].

With the recent development trends of high power output and simultaneously light weight of the diesel engine, the working conditions for the cylinder gasket become even more critical. The cylinder gasket of the diesel engine now needs not only to ensure high durability and reliability, but also to correspond to a narrow land between the cylinder bores, minimize cylinder bore distortion and decrease crevice volume. In order to meet the requirements, the use of metal cylinder gaskets is rapidly increasing in modern engines [7-15].

In this paper, finite element numerical simulation and pressure experiment of the metal cylinder gasket were as the research object. The tests were conducted to verify the accuracy of three distinct cylinder gasket pressure simulation models. According to the experimental results of cylinder gasket compression rebound curve, the gasket element model was constructed. The influence of bolt preload, cylinder block and 
cylinder head material on gasket sealing pressure was analyzed systematically under the thermal-mechanical coupling condition, and in the end the different factors were investigated.

\section{Testing}

\subsection{Material Property Test}

For the requirement of $22 \mathrm{MPa}$ combustion pressure, the cylinder gasket was designed as a metal single-ring in order to meet the high strength and high sealing effect of combustion composite structure. Fig. 1 shows the test device for gasket material property test. The Zwick-100 KN material testing machine was used to test the compression and rebound performance of cylinder gasket at room temperature. Then the program compiling and curve drawing was conducted by using the compression and rebound test data with MATLAB software.



Figure 1: Test set-up for gasket material property

The loading and unloading curves of metal gasket were studied. According to the test, the compression curve was different from the rebound curve. Therefore a mathematical equation reflecting the real stressstrain relationship of the gasket was proposed to distinguish the loading and unloading stages [16]:

The compression curve equation

$\sigma=a_{1} \varepsilon+a_{2} \varepsilon^{2}+a_{3} \varepsilon^{3}+a_{4} \varepsilon^{4}+a_{5} \varepsilon^{5}+a_{6} \varepsilon^{6}$

where $\sigma$ is stress, $\varepsilon$ is strain, $\mathrm{a}_{1}, \mathrm{a}_{2}, \mathrm{a}_{3}, \mathrm{a}_{4}, \mathrm{a}_{5}$ and $\mathrm{a}_{6}$ are regression coefficient from experiment.

The rebound curve equation

$\sigma=\alpha \exp (\beta \varepsilon)+\gamma$

$\alpha=\frac{\sigma_{y}}{\exp \left(\beta \varepsilon_{y}\right)-\exp \left(\beta \varepsilon_{r}\right)}$

$\beta=\mathrm{a} \cdot \exp \left(\mathrm{b} \varepsilon_{y}\right)+\mathrm{c}$

$\gamma=-\alpha \cdot \exp \left(\beta \varepsilon_{r}\right)$

$\varepsilon_{r}=P \varepsilon_{y}^{2}+q \varepsilon_{y}$

where $\sigma_{\mathrm{y}}$ is gasket stress at start of unloading, $\varepsilon_{\mathrm{y}}$ is gasket strain at start of unloading; $\varepsilon_{\mathrm{r}}$ is residual strain, a, b, $\mathrm{c}, \mathrm{P}$ and $\mathrm{q}$ are regression coefficient from experiment. 
For the same cylinder gasket, the regression coefficient of cylinder gasket was obtained from compression and rebound test data. The regression coefficient, stress and strain of cylinder gasket were further brought into the rebound equation, and the rebound curve of cylinder gasket was produced. The above curve equation was trained through the compression rebound test data of cylinder gasket. Fig. 2 shows the gasket compression rebound and material nonlinear stress-strain curve. The test curve would be used to construct the gasket element model to accurately simulate the mechanical behavior of cylinder gasket under the preloaded and explosion conditions of diesel engine composite structure.
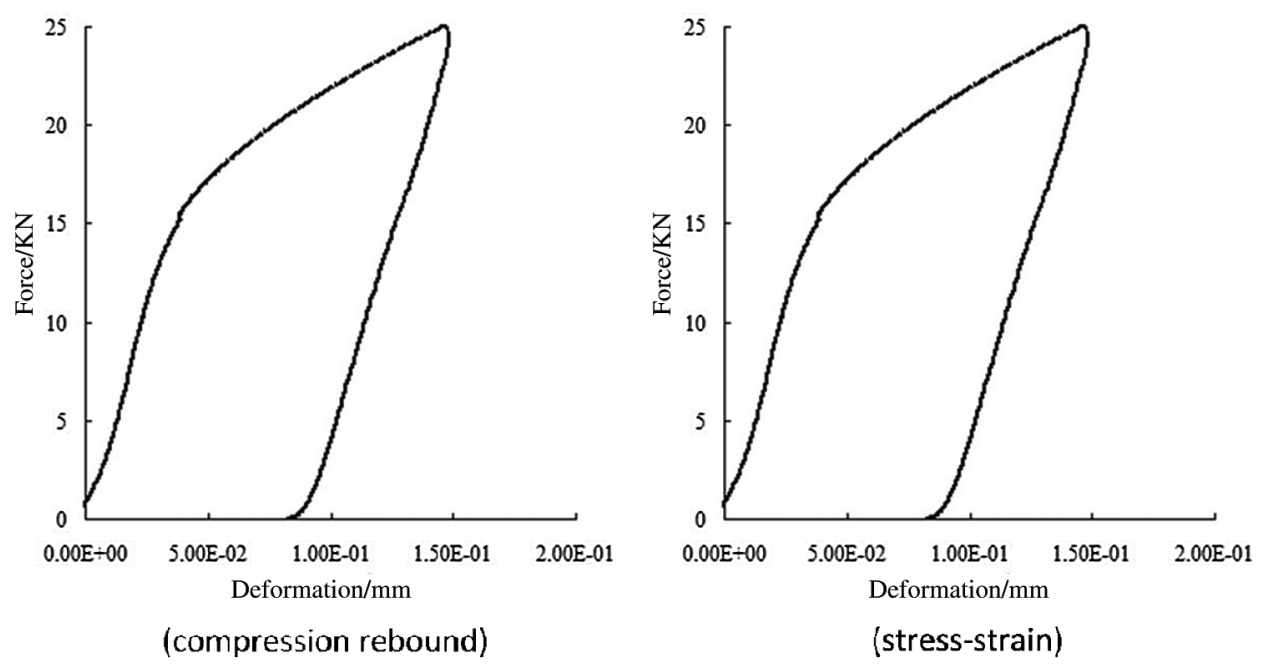

Figure 2: Gasket compression rebound and stress-strain curve

\subsection{Pressure Test}

As shown in Fig. 3, the experiment platform included engine, pressure transducer slices, scanners and computer data analysis software. The pressure transducer slices were placed on the cylinder gasket, and the bolt pre-tightening force of $50 \mathrm{~N} . \mathrm{m}+180^{\circ}$ was applied to simulate the working condition of cylinder gasket. Then the pressure distribution data were obtained by scanning the pressure sensor slices with the scanner and data analysis software. The test data in Fig. 4 showed the pressure distribution and stress value of cylinder gasket on the combustion sealing zone, which provided the basis for the model verification and the sealing performance study of the cylinder gasket.
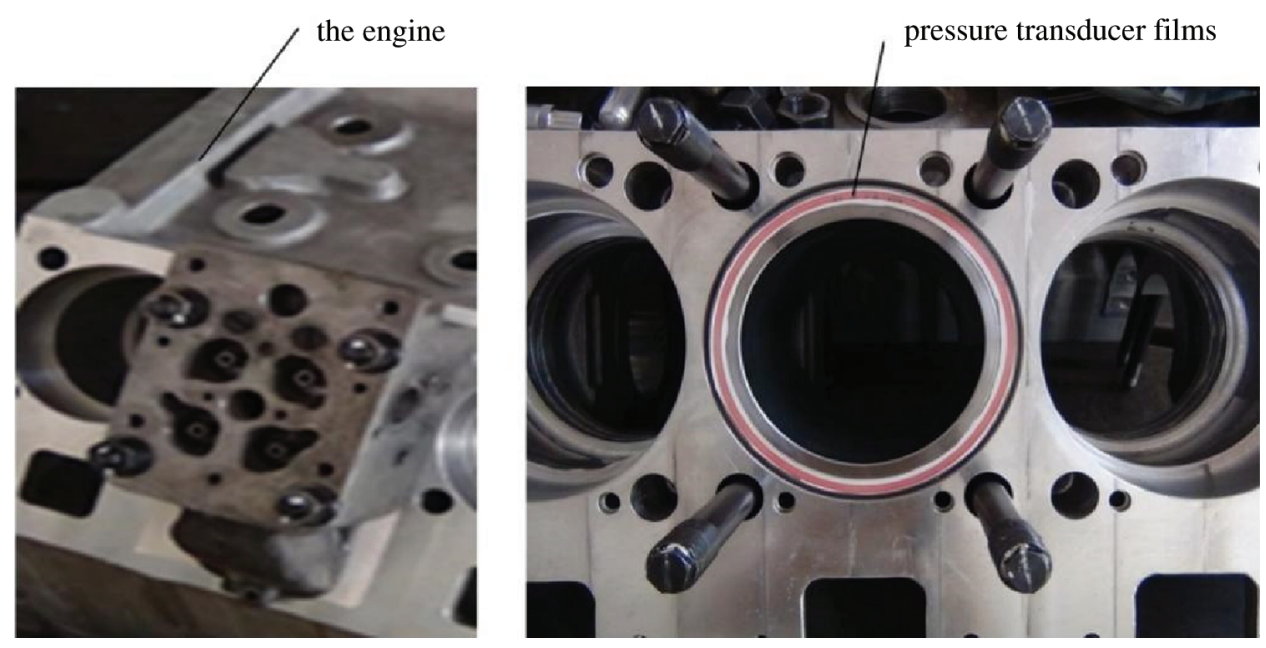

Figure 3: Test set-up for cylinder gasket pressure 




Figure 4: Test date for gasket pressure

\section{Numeration Model}

The FE model of diesel engine assembly was analyzed by ABAQUS software in Fig. 5. In the FE model was meshed by 1183775 elements and 520524 nodes. The materials of cylinder block, cylinder head, cylinder liner and bolt were defined as Aluminum Alloy, RuT300, Gray iron and 45 steel, respectively. The cylinder gasket was designed as elastic model, plastic model and gasket element model in order.

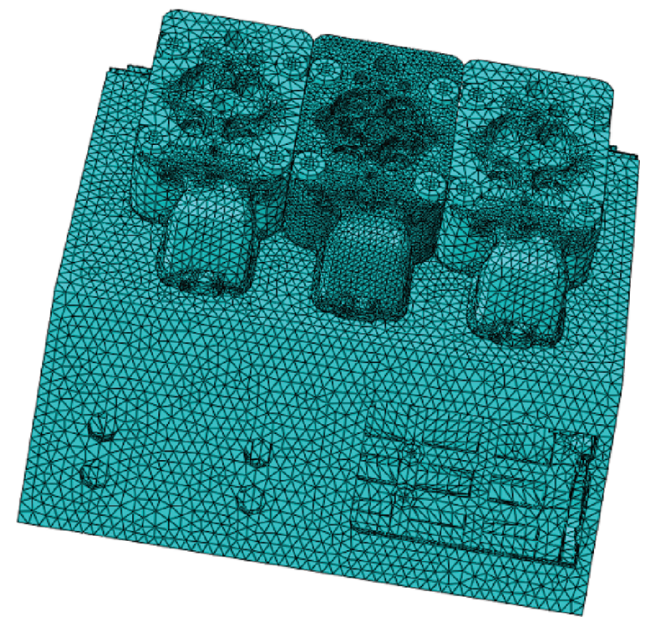

Figure 5: The discrete model of cylinder gasket sealing system 


\subsection{Boundary Conditions}

\section{(1) Constraint and Contact Condition}

According to the assembly of engine, the lower surface of engine block were fixed in $\mathrm{x}, \mathrm{y}, \mathrm{z}$ direction.

The contact model was divided into two parts including the contact between the engine block, cylinder head and the cylinder gasket and the contact between the engine block, cylinder head and the bolt.

(2) Mechanical and Thermal Load Condition

For the FE model, the preloads of bolts, the gas pressure and the thermal loads were applied. The temperature and heat transfer coefficient of gas and coolant calculated by CFD were taken as boundary conditions and assigned to FEA heat transfer calculation model by surface method in ABAQUS software.

\subsection{Model Validation}

In order to study influence of cylinder gasket on sealing performance, the cylinder gasket model was defined as elastic, nonlinear elastic-plastic and gasket element respectively. The calculation results mainly investigated the cylinder gasket contact stress, and the measuring points were shown in Fig. 6. 3 and 7 measuring points were in the line of cylinder center, 5 and 1 measuring points were in the internal and external sides of engine block, 2 and 8 measuring points were close to the bolts positions of cylinder head intake side, and 4 and 6 measuring points were adjacent to the bolts positions of cylinder head exhaust side. The calculation results of three cylinder gasket simulation models were shown in Figs. 7-9. Tab. 1 shows the Stress distribution of cylinder gasket from experiment and FEA.

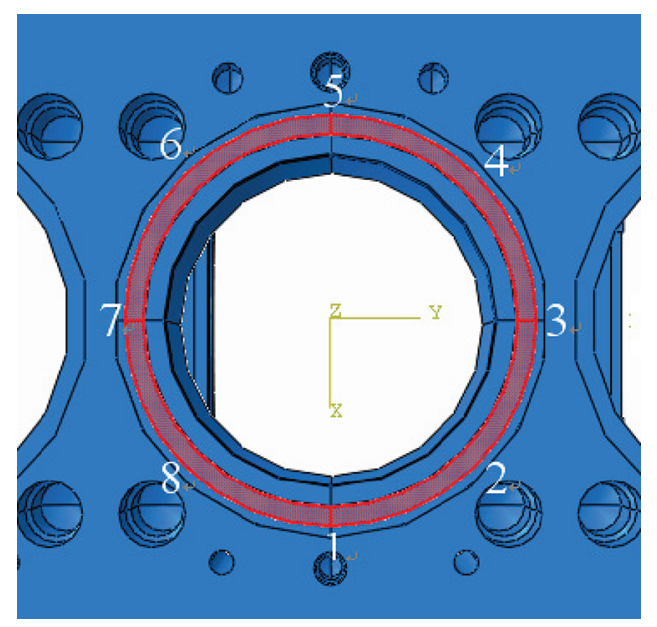

Figure 6: Measuring points for gasket stress

The results show that elastic, elastic-plastic and gasket element material simulation models were consistent with the test data, and the maximum difference was less than $5 \%$. Therefore gasket element model could be used for subsequent study on the sealing performance of the cylinder gasket.

\subsection{Thermo-Mechanical Coupling Model}

Because the cylinder gasket not only bear the bolt preload, but also bear the explosion pressure and high thermal load. Thus it is more favorable to use the thermal-mechanical coupling gasket element model to study the sealing performance of cylinder gasket in subsequent projects. The stress distribution results of thermal-mechanical coupling model were higher than mechanical model, and the stress distribution result for cylinder gasket was shown in Fig. 10. 


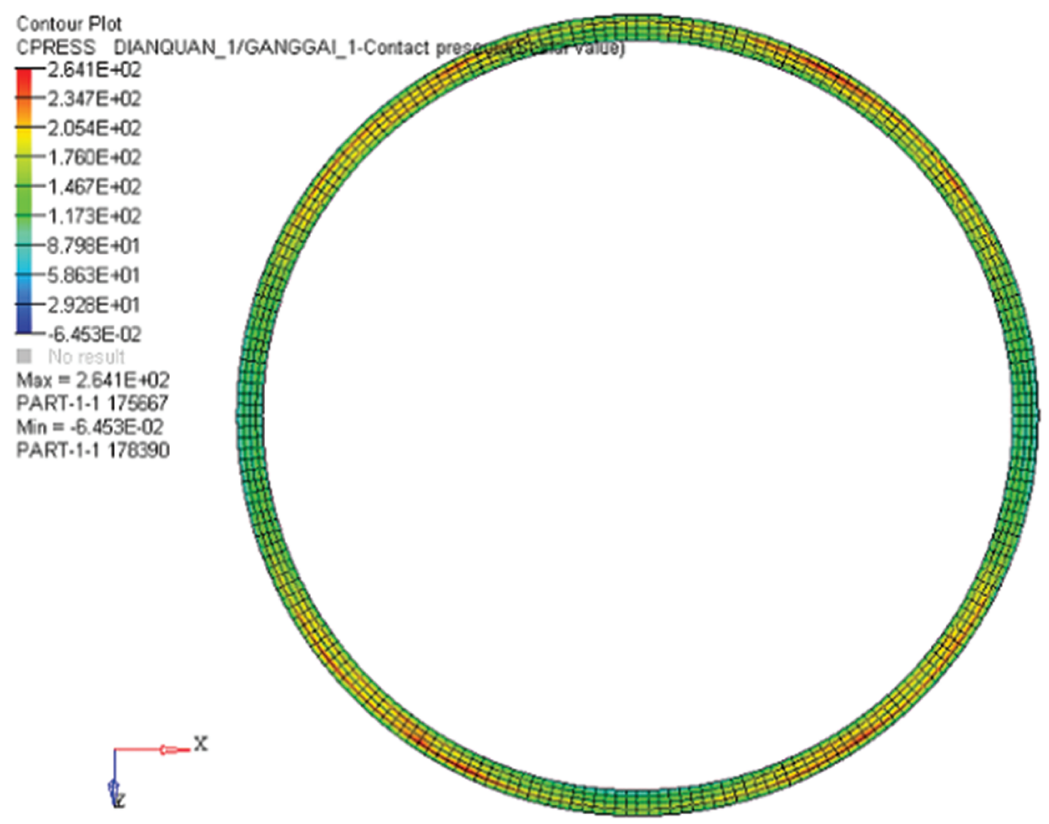

Figure 7: Stress distribution for gasket elastic material

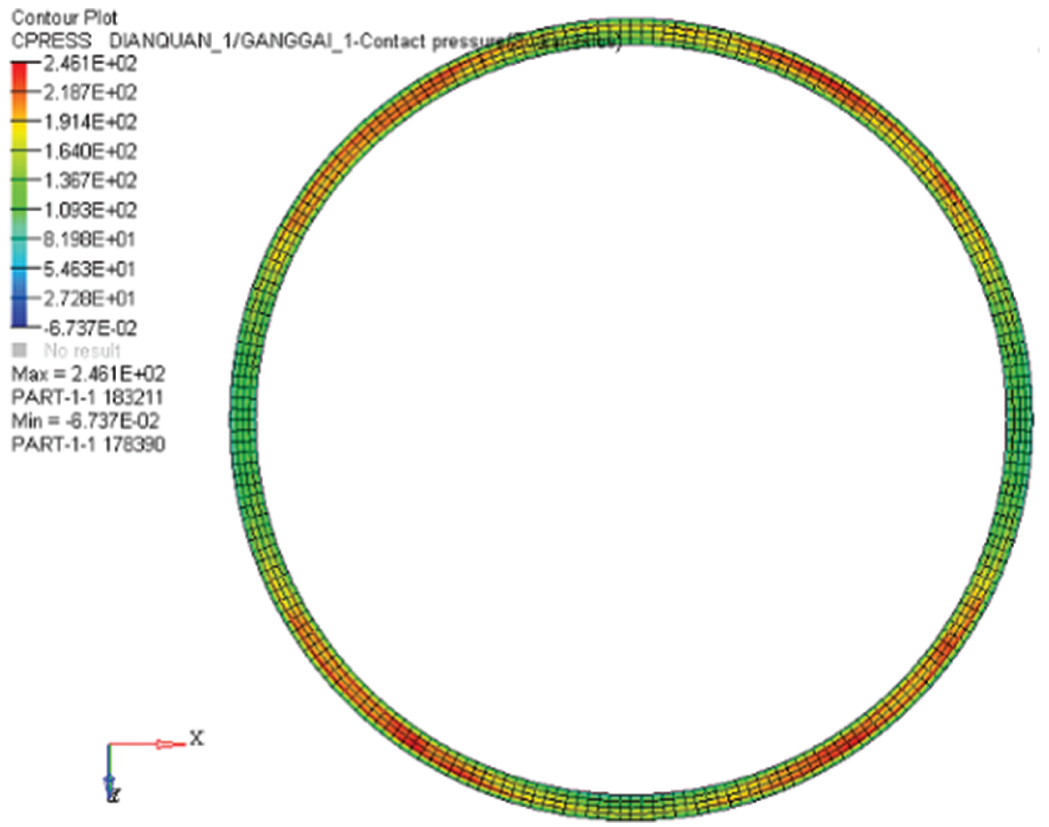

Figure 8: Stress distribution for gasket plastic material

\section{Analysis of Simulation Results}

Fig. 11 shows the stress curve of bolt preload including increasing load from $90 \mathrm{KN}$ to $100 \mathrm{KN}, 110 \mathrm{KN}$, $120 \mathrm{KN}$ and $140 \mathrm{KN}$. The results show that, with the increase of bolt preload, the sealing pressure of cylinder gasket has a significant increase trend, and the changing rate is about $11 \%$. The cylinder gasket stresses of 2 , 4, 6 and 8 measuring points are larger because these points are close to the bolt, which indicates that bolt 
preload is the most important influence factors affecting the sealing pressure of cylinder gasket. Accordingly, the sealing pressure of cylinder gasket can be adjusted by changing the bolt preload.

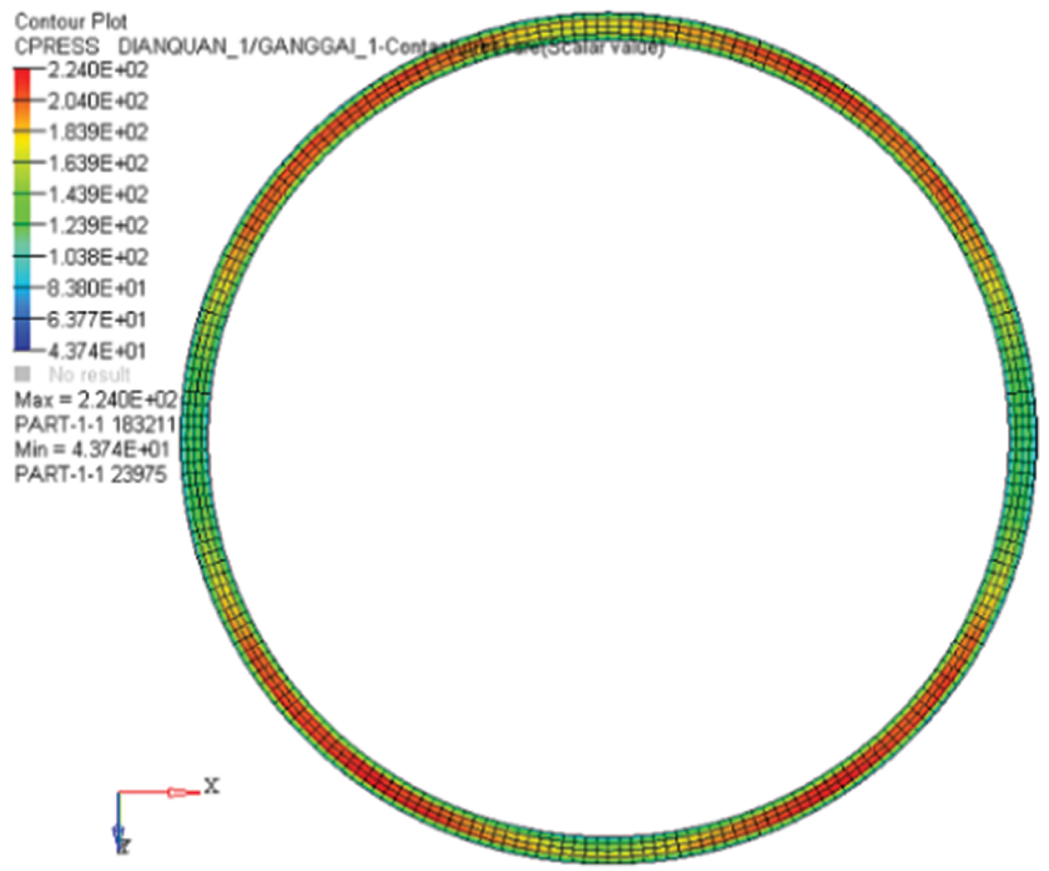

Figure 9: Stress distribution for gasket element material

Table 1: Stress distribution of cylinder gasket from experiment and FEA

\begin{tabular}{llllllll}
\hline \multirow{2}{*}{$\begin{array}{l}\text { Location } \\
\text { Experiment } \\
(\mathrm{MPa})\end{array}$} & $\begin{array}{l}\text { Elastic } \\
\text { material } \\
(\mathrm{MPa})\end{array}$ & $\begin{array}{l}\text { Elastic- } \\
\text { plastic } \\
\text { material } \\
(\mathrm{MPa})\end{array}$ & $\begin{array}{l}\text { Gasket } \\
\text { element } \\
\text { material } \\
(\mathrm{MPa})\end{array}$ & $\begin{array}{l}\text { Elastic } \\
\text { material }\end{array}$ & $\begin{array}{l}\text { Elastic- } \\
\text { plastic } \\
\text { material }\end{array}$ & $\begin{array}{l}\text { Gasket } \\
\text { element } \\
\text { material }\end{array}$ \\
\hline 1 & 177 & 168.5 & 181.1 & 185.0 & 4.8 & 2.3 & 4.52 \\
2 & 199 & 242.4 & 221.3 & 208.1 & 21.8 & 11.2 & 4.6 \\
3 & 139.5 & 158.5 & 126.4 & 135.4 & 13.6 & 9.4 & 2.93 \\
4 & 201 & 257.1 & 228.3 & 204.0 & 27.9 & 13.5 & 1.49 \\
5 & 193.5 & 167.4 & 182.4 & 184.2 & 13.4 & 5.7 & 4.8 \\
6 & 190.5 & 259.2 & 229.1 & 199.7 & 36 & 20.2 & 4.82 \\
7 & 140.5 & 157.4 & 129.1 & 137.9 & 12 & 8.1 & 1.85 \\
8 & 227 & 253.2 & 225.7 & 223.6 & 11.5 & 0.57 & 1.49 \\
\hline
\end{tabular}

Fig. 12 shows the influence curve of cylinder block material on sealing pressure of cylinder gasket when steel is substituted as vermicular iron, titanium alloy, gray iron and cast aluminum. Tab. 2 shows the physical properties of the materials. As can be seen from Fig. 12, the change of cylinder block material has negligible 
influence on the sealing pressure of each measuring point, but the overall weight of composite structure greatly reduced when using cast aluminum material. It can be considered when selecting materials in engineering.

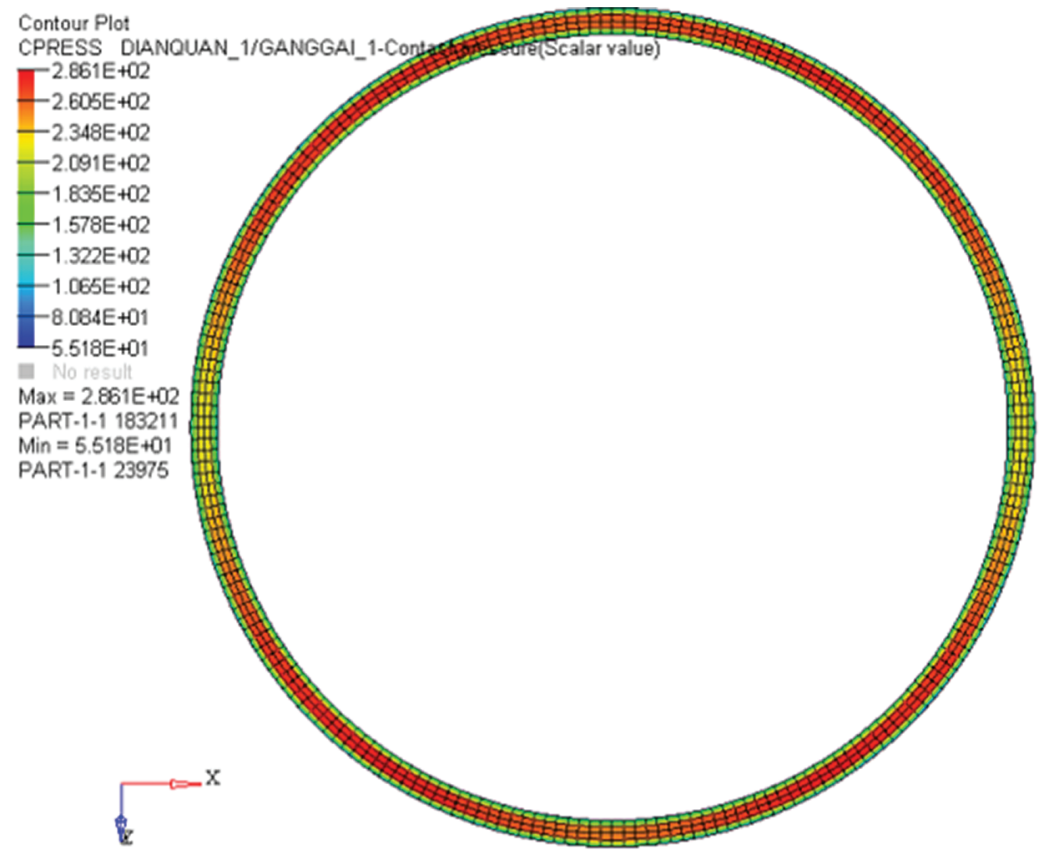

Figure 10: Stress distribution for gasket thermo-mechanical coupling

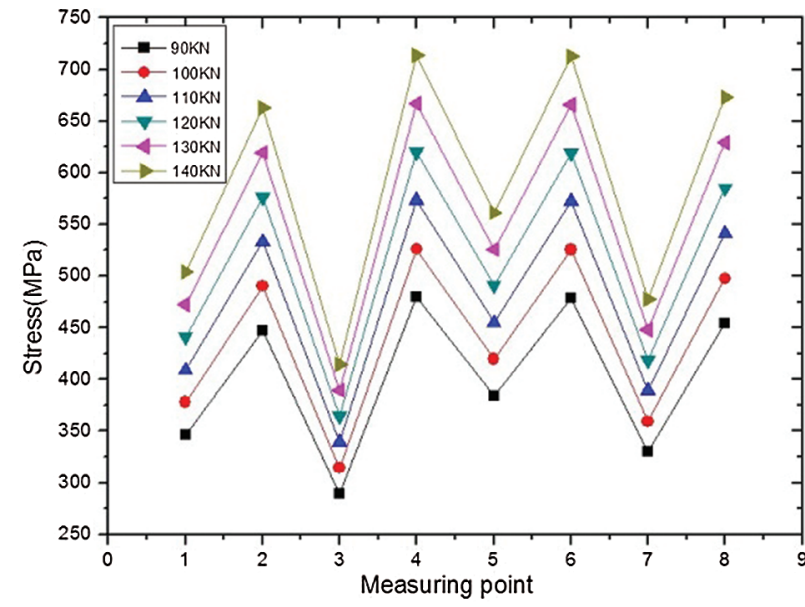

(Preloaded condition)

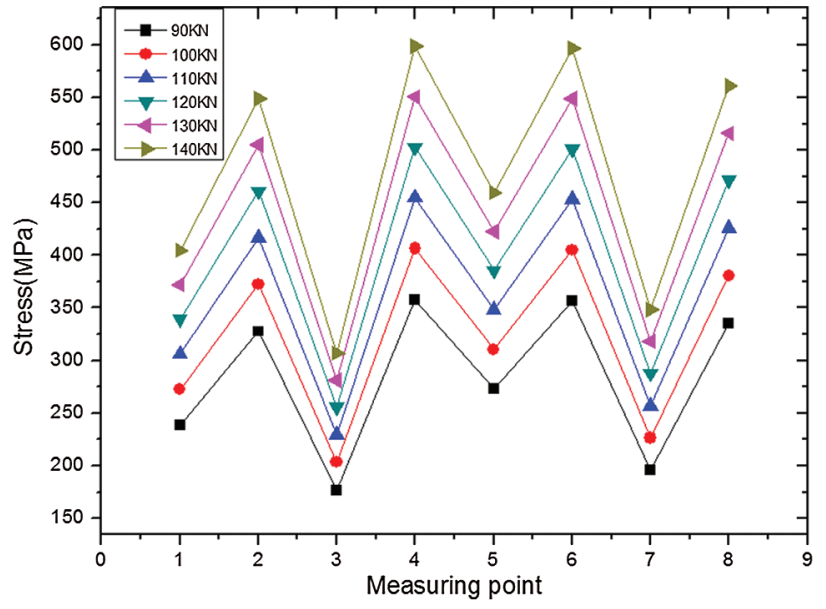

(Explosion condition)

Figure 11: Stress curve for bolt preload changing

Fig. 13 gives the impact curve of the cylinder gasket sealing pressure, for different materials from steel to vermicular iron, titanium alloy, gray iron and cast aluminum. It can be seen from Fig. 12 that the change of cylinder head material has a certain effect on the sealing pressure of cylinder gasket, and the sealing pressure 
of cylinder gasket decrease with the decrease of material elastic modulus of cylinder head. Therefore the material selection of cylinder head should meet the minimum sealing pressure and reasonable economy.

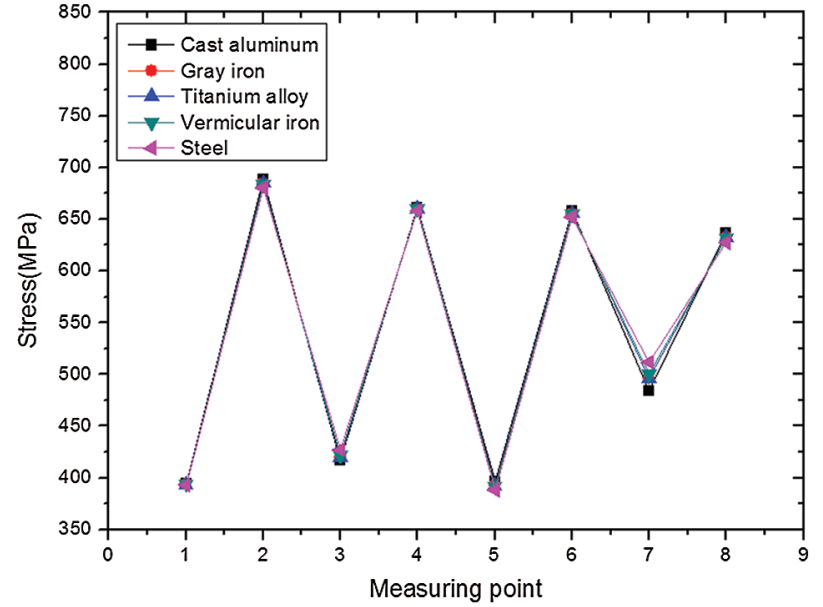

(Preloaded condition)

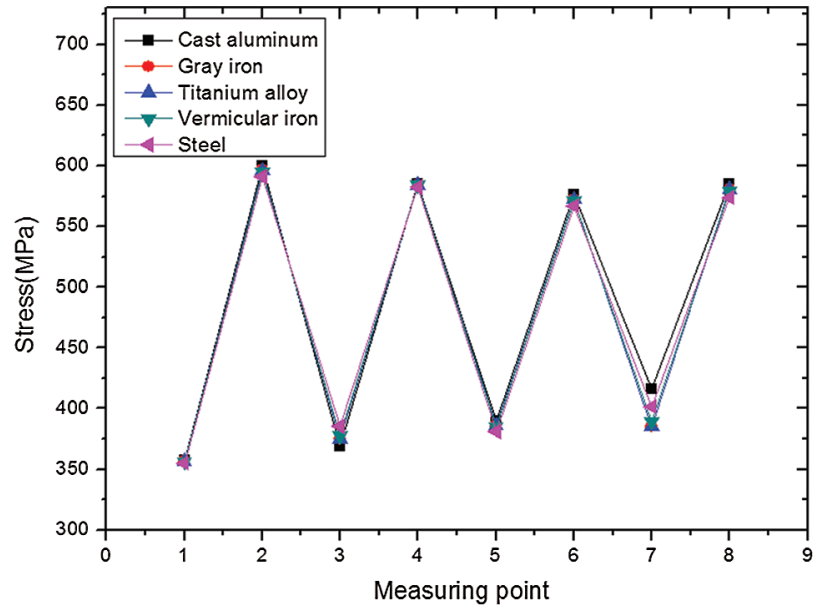

(Explosion condition)

Figure 12: Stress curve for the material changing of cylinder block

Table 2: Material physical parameters

\begin{tabular}{llll}
\hline Material & Young's modulus $(\mathrm{GPa})$ & Poisson's ratio & Density $\left(\mathrm{kg} \cdot \mathrm{m}^{-3}\right)$ \\
\hline Cast aluminum & 71 & 0.3 & $2.7 \times 10^{3}$ \\
Gray iron & 105 & 0.27 & $7.1 \times 10^{3}$ \\
Titanium alloy & 110 & 0.3 & $4.5 \times 10^{3}$ \\
Vermicular iron & 130 & 0.28 & $7.1 \times 10^{3}$ \\
Steel & 206 & 0.28 & $7.8 \times 10^{3}$ \\
\hline
\end{tabular}

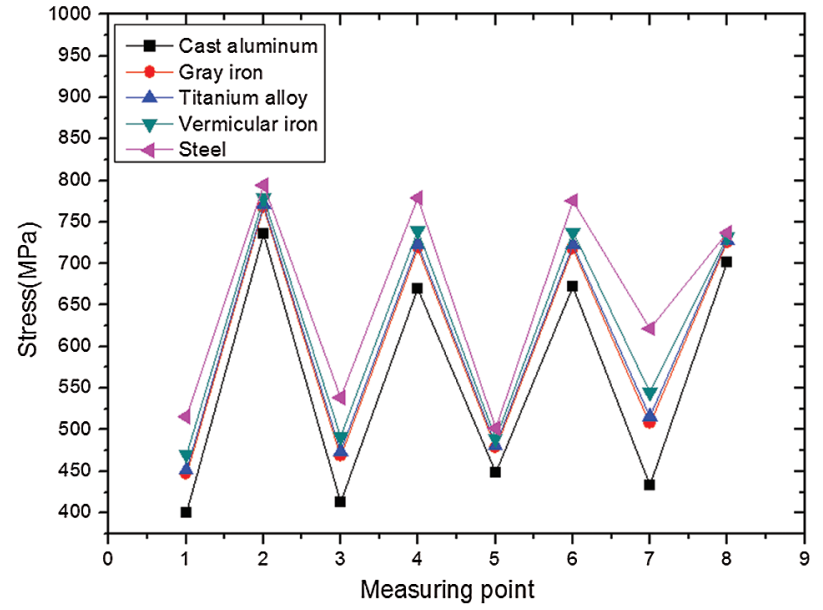

(Preloaded condition)

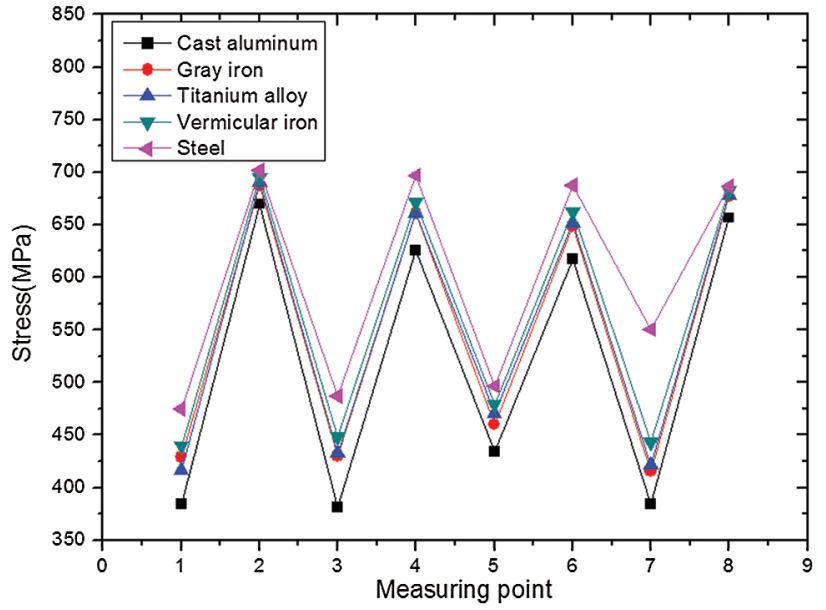

(Explosion condition)

Figure 13: Stress curve for the material changing of cylinder head 


\section{Conclusions}

(1) Based on the measured compression rebound curve of cylinder gasket, nonlinear mechanical properties of the cylinder gasket material were studied, and the gasket element was constructed. The pressure test of cylinder gasket verified the gasket model reliability, which provided theoretical support for further research on the sealing performance of thermal-mechanical coupling for cylinder gasket.

(2) The change of bolt preload force contributed greatly to the sealing pressure of cylinder gasket, and it was further verified that the uniformity of cylinder gasket could be adjusted by changing the pre-tightening force. It had certain reference value for the design of cylinder gasket sealing structure.

(3) The effect of changing the cylinder block material on the sealing pressure of cylinder gasket was not obvious. The sealing pressure of cylinder gasket decreased sequentially with the decrease of elastic modulus of the cylinder head material. It could be considered as the reference when selecting materials for the block and cylinder head in the engineering.

Funding Statement: This work was supported by the Medium and Heavy Duty High Power-Density Clean Energy Power of National 863 Project.

Conflicts of Interest: The authors declare that they have no conflicts of interest to report regarding the present study.

\section{References}

1. He, L., Zuo, Z. X., Xiang, J. H. (2014). Effect of bolts assembly connection process on sealing performance of cylinder. Transactions of CSICE, 32(6), 562-568.

2. Sangle, D. R., Ozarde, A., McNay, G. (2019). Cylinder head gasket fretting simulation for high horse power engine. SAE International Journal of Advances and Current Practices in Mobility, 1, 133-136.

3. Brewer, T., Chen, X. (2017). Cylinder head gasket fretting/scrub mechanism investigation and analysis procedure developments, SAE Technical Paper.

4. Farfan-Cabrera, L., Rodríguez-Bravo, G., Vega-Moron, R., Calderón, C. R., Godínez-Salcedo, J. (2020). Crevice corrosion accelerated test for cylinder head/gasket/monoblock assemblies from lightweight engines considering overheating effects, SAE Technical Paper.

5. Wei, Y., Yang, S., Shi, X., Li, J., Lu, X. (2017). Finite element analysis of cylinder gasket under cylinder pressure and structural optimization of the cylinder gasket, SAE Technical Paper.

6. Tian, L., Fang, Z. (2019). Review of the special issue on efd and heat transfer. Fluid Dynamics \& Materials Processing, 15(4), 285291.

7. Ren, M., Shu, X. (2020). A novel approach for the numerical simulation of fluid-structure interaction problems in the presence of debris. Fluid Dynamics \& Materials Processing, 16(5), 979-991. DOI 10.32604/fdmp.2020.09563.

8. Santra, T., Agarwal, V. K. (2015). Sealing prediction and improvement at cylinder head \& block interface under thermo-mechanical loading involving multi-layer steel gasket. SAE Technical Paper.

9. Yamaguchi, K., Sato, A., Goto, E., Fujiki, R., Nakata, K. (1998). Development of a new metal cylinder head gasket. SAE Technical Paper.

10. Hamada, N., Suzuki, K. (2014). A study on corrosion occurring at the sealing gap between aluminum alloy and rubber gasket, SAE Technical Papers.

11. Sato, K., Nishiyama, T., Murakami, O., Kunieda, K., Chiba, Y. (2009). Strength analysis of a cylinder head gasket using computer simulation. SAE International Journal of Materials and Manufacturing, 2(1), 92-98.

12. Wan, X., Ni, J. M., Michael, B. (2009). Nonlinear finite element analysis of cylinder head cover gasket. Chines Internal Combustion Engine Engineering, 30(5), 88-92.

13. Nassar, S. A., Matin, P., Barber, G. C. (2005). Thread friction torque in bolted joints. Journal of Pressure Vessel Technology, 127(4), 387-393. DOI 10.1115/1.2042474. 
14. Sayed, A. N., Ali, A. A. (2006). Clamp load loss due to elastic interaction and gasket creep relaxation in bolted joints. Journal of Pressure Vessel Technology, 128(3), 394-401. DOI 10.1115/1.2218343.

15. Marshall, M. B., Lewis, R., Dwyer-Joyce, R. S. (2006). Characterisation of contact pressure distribution in bolted joints. Strain, 42(1), 31-43. DOI 10.1111/j.1475-1305.2006.00247.x.

16. Takaki, T., Fukuoka, T. (2000). Bolt-up strategy for pipe flange connections using finite element analysis. ASME-Publications-PVP, 405, 143-150. 